\title{
Avaliação da citotoxicidade de dois cimentos à base de MTA: um estudo in vitro
}

\author{
Cytotoxicity evaluation of two MTA-based root canal sealers: an in vitro study
}

\begin{abstract}
Fernanda Cunha Marins, ${ }^{1}$ Carina Taboada Ronconi, ${ }^{1}$ Flávia Medeiros Saavedra, ${ }^{2}$ Ana Beatriz Machado Lima, ${ }^{1}$ Alexandre Augusto Zaia, ${ }^{2}$ Edson Jorge Lima Moreira, Emmanuel João Nogueira Leal da Silva ${ }^{1}$

${ }^{1}$ Departamento de Endodontia, Faculdade de Odontologia, Universidade do Grande Rio, Duque de Caxias, RJ, Brasil

2Departamento de Endodontia, Faculdade de Odontologia, Universidade Estadual de Campinas, Piracicaba, SP, Brasil

- Os autores declaram que não há conflito de interesse.

\section{Resumo}

Objetivo: avaliar o potencial citotóxico de dois cimentos endodônticos à base de MTA (Endoseal e MTA Fillapex), em culturas de fibroblastos humanos, comparando-os com o cimento de referência à base de resina (AH Plus). Material e Métodos: os materiais obturadores foram preparados e eluídos em meio de cultura celular durante 24 horas à $37^{\circ} \mathrm{C}$ em estufa de $\mathrm{CO}_{2}$. Foram feitas quatro diluições distintas destes meios nas concentrações 1:1, 1:2, 1:4, 1:8 e expostos à cultura celular de fibroblastos humanos da linhagem MRC-5 por 24 horas. A citotoxicidade destes meios de cultura foi avaliada utilizando o ensaio MTT. Os resultados foram transformados em porcentagens de células viáveis com relação ao grupo controle negativo e analisados estatisticamente a partir da Análise de Variância (ANOVA) e pelo teste de Tukey utilizando o software SPSS 15.0 (SPSS Inc, Chicago,IL) $(P<0,05)$. Resultados: na diluição 1:1 não houve diferença estatística entre os cimentos testados $(P>0,05)$. Na diluição 1:2 o AH Plus apresentou menor toxicidade quando comparado aos demais cimentos testados $(P<0,05)$. Nas concentrações de 1:4 e 1:8 o MTA Fillapex apresentou maior citotoxicidade quando comparado ao AH Plus e ao EndoSeal $(P<0,05)$. Nessas concentrações não foram observadas diferenças estatísticamente significantes entre o AH Plus e o EndoSeal $(P>0,05)$. Conclusão: a citotoxicidade dos cimentos endodônticos avaliados foi dose dependente. O Endoseal foi menos tóxico que o MTA Fillapex em duas das quatro diluições testadas. Além disso, o AH Plus apresentou citotoxicidade inferior aos dois cimentos à base de MTA em uma das quatro diluições avaliadas.
\end{abstract}

Palavras-chave: Materiais restauradores do canal radicular; Ligamento periodontal; Citotoxicidade.

\section{Abstract}

Objective: this study evaluated the cytotoxic effects of two MTA-based root canal sealers (Endoseal and MTA Fillapex) on human MRC-5 fibroblasts by comparing cell viability with an epoxy resin-based sealer (AH Plus) and negative control. Material and Methods: MRC-5 human fibroblasts were incubated with four different elutes of Endoseal, MTA Fillapex, and AH Plus for 24 hours. The cytotoxicity of tested materials was determined using the MTT assay. The results were analyzed using ANOVA and Tukey tests using SPSS software 15.0 (SPSS Inc, Chicago, IL). The level of significance was $P<0.05$. Results: at 1:1 dilution, there was no statistical difference between all root canal sealers tested $(P>0.05)$. AH Plus showed significantly more cell viability (mitochondrial activity of cells) than Endoseal and MTA Fillapex at 1:2 dilution ( $P<0.05)$. At 1:4 and 1:8 dilutions, MTA Fillapex showed less cell viability than AH Plus and EndoSeal $(P<0.05)$. At these same dilutions, no statistically significant differences were observed between AH Plus and EndoSeal $(P>0.05)$. Conclusion: the cytotoxicity effects of all endodontic root canal sealers were dose-dependent. Endoseal showed significantly more cell viability than MTA Fillapex in two of four dilutions tested. AH Plus showed statistically lower cytotoxicity than the two MTA-based root canal sealers in one of four dilutions evaluated. Keywords: Root canal Filling Materials; Periodontal Ligament; Cytotoxicity.

\section{Introdução}

A obturação do sistema de canais radiculares tem como objetivo o total preenchimento do sistema de canais radiculares recém-descontaminados, a fim de impedir a microinfiltração bacteriana do meio oral, dos tecidos apicais e periapicais para o interior dos mesmos. ${ }^{1,2}$ Convencionalmente, a obturação é composta pela utilização de cones de guta-percha em combinação com algum cimento endodôntico. A principal função do cimento é preencher espaços existentes entre a guta-percha e as paredes do canal radicular. ${ }^{2}$

Os cimentos endodônticos podem ser encontrados comercialmente em diversas formulações. Contudo, independente de seus componentes, tais materiais devem contemplar algumas propriedades importantes, tais como a sua boa tolerância pelos tecidos periapicais, uma vez que os cimentos endodônticos podem permanecer em contato íntimo com os tecidos periapicais por um período prolongado, devido a sua possível extrusão através do ápice ou por subprodutos da sua degradação que podem percolar através de canais laterais, acessórios ou forame apical, alcançando assim, os tecidos circundantes. ${ }^{3-5}$
O Agregado Trióxido Mineral (MTA) é um material que possui propriedades biológicas e fisico-químicas adequadas para o seu uso na Endodontia, ${ }^{6,7}$ sendo considerado um material próximo do ideal em termos de biocompatibilidade. ${ }^{6-8}$ Com base nas características biológicas favoráveis do MTA e buscando melhorar as desvantagens físicas da formulação do MTA convencional, novos cimentos obturadores a base de MTA foram lançados no mercado odontológico. O EndoSeal (Maruchi, Wonju, Coréia do Sul) e o MTA Fillapex (Angelus,Londrina, PR, Brasil) são exemplos de cimentos endodônticos à base de MTA. O MTA Filapex é um cimento endodôntico composto de duas pastas. Após sua manipulação, este cimento consiste em MTA, resina salicilato, resina natural, resina siluente, tungstato de cálcio e sílica nanoparticulada. Já o cimento endodôntico Endoseal é um cimento pré-manipulado que possui em sua composição basicamente silicatos de cálcio, aluminatos de cálcio e aluminoferrites de cálcio. Diversos estudos encontrados na literatura endodôntica indicam o potencial citotóxico do MTA Fillapex, ${ }^{5,9-13}$ contudo o cimento Endoseal ainda pode ser considerado um material pouco estudado.

Sendo assim, o presente trabalho tem por objetivo verificar os 
efeitos citotóxicos dos cimentos endodônticos à base de MTA (Endoseal e MTA Fillapex), sendo o cimento endodôntico AH Plus (Maillefer Dentsply, Ballaigues, Suiça) utilizado como material de referência para comparação. A hipótese nula é de que não há diferença estatisticamente significante entre os efeitos citotóxicos dos materiais avaliados.

\section{Material e Métodos}

\section{Materiais Endodônticos}

Os cimentos endodônticos utilizados foram: AH Plus, Endoseal e MTA Fillapex. Discos de cada material foram preparados sob condições assépticas em um molde se silicone estéril e inerte, conforme a norma ISO 10993-12, com 5 mm de diâmetro e 2 mm de altura. Os materiais foram acondicionados por 24 horas em estufa a $37^{\circ} \mathrm{C}$, para que tomassem presa e fosse possível realizar a remoção dos moldes de silicone. O material excedente foi removido com um bisturi estéril. Após a remoção, os cimentos endodônticos foram armazenados em meio Dulbecco's Modified Eagle's Médium - DMEM (PAA, Germany) com 10\% soro fetal bovino, penicilina e estreptomicina a $37^{\circ} \mathrm{C}$ em um estufa de $\mathrm{CO}_{2}\left(5 \% \mathrm{CO}_{2}\right)$ por 24 horas. A eluição foi realizada utilizando uma razão entre a superfície do cimento e o volume do meio de aproximadamente $150 \mathrm{~mm}^{2} / \mathrm{mL}$.

\section{Cultura Celular}

As células utilizadas neste estudo foram os fibroblastos humanos imortalizados da linhagem MRC-5. Estas células foram inicialmente cultivadas em meio DMEM com 10\% soro fetal bovino, penicilina e estreptomicina a $37^{\circ} \mathrm{C}$ em uma estufa de $\mathrm{CO}_{2}(5 \%$ $\mathrm{CO}_{2}$ ). Um total de $1 \times 10^{5}$ células foram cultivadas em cada um dos poços de uma placa de cultura com 24 poços, respectivamente, por 24 horas. A contagem foi realizada em câmera de Neubauer e a viabilidade dessas células confirmada com corante Azul de Tripan (Sigma, EUA). As células foram colocadas nessas placas 24 horas antes de iniciar o experimento, para formação de uma monocamada celular com, aproximadamente, $80 \%$ de confluência. As células foram, então, expostas aos extratos dos materiai obturadores por um período de 24 horas. O controle negativo fc a linhagem celular sem a exposição às eluições dos materiais ob turadores endodônticos.

\section{Ensaio de MTT}

As avaliações de citotoxicidade foram realizadas de acordo con as normas de padrão internacional ISO. A avaliação dos materiai foi realizada através da incubação das culturas de células com a eluções dos cimentos endodônticos de acordo com a norma ISC 10993-5. A atividade mitocondrial foi quantificada a partir do $\mathrm{Ki}$ MTT Assay (ATCC, VA). Este ensaio foi realizado com o objetivı de verificar a viabilidade celular em quatro diluições diferente dos cimentos endodônticos em meio de cultura (1:1, 1:2, 1:4, 1:8)

Foi estabelecido como padrão 1:1 uma proporção entre a área dos cimentos/ o volume de meio de $150 \mathrm{~mm}^{2} / \mathrm{ml}$. Após o período de 24 horas para a presa dos materiais, as diluições seriadas foram realizadas a partir da elução 1:1 (área dos cimentos/meio na pro- porção), acrescendo-se sempre meio de cultura DMEM, obtendose assim as diluições 1:2, 1:4, 1:8. Estas eluições foram deixadas em contato com as culturas celulares por outro período de $24 \mathrm{~h}$ sob $37^{\circ} \mathrm{C}$ em uma estufa umidificada sob atmosfera de ar ambiente contendo $5 \%$ de $\mathrm{CO}_{2}$. Em seguida foi realizado o ensaio de MTT para verificar a viabilidade celular. As amostras de controle negativo foram tradas nas mesmas condições, contudo, expostas ao meio de cultura normal.

Após o contato das células com as eluições dos materiais obturadores, o meio foi aspirado as células foram lavadas duas vezes com $1 \mathrm{ml}$ de PBS estéril. Foi adicionado a todos os poços $1 \mathrm{ml}$ da solução de MTT $(0,5 \mathrm{mg} / \mathrm{ml})$. Após a incubação por $2 \mathrm{~h}$, foi retirada toda a solução de MTT e foi adicionado a todos os poços $500 \mu \mathrm{l}$ de DMSO estéril. As placas foram agitadas em um vortex durante 5 minutos e em seguida permaneceram imóveis por mais 5 minutos para a estabilização da cor. Foram, então, retiradas alíquotas de $100 \mu \mathrm{l}$ de cada uma das amostras, as quais foram transferidas para uma placa de 96 poços para a leitura no leitor de microplaca. A absorbância foi medida em $540 \mathrm{~nm}$.

\section{Análise Estatística}

Os dados foram analisados estatisticamente a partir da Análise de Variância (ANOVA) e pelo teste de Tukey utilizando o software SPSS 15.0 (SPSS Inc, Chicago, IL). O nível de significância utilizado foi de $P<0,05$.

\section{Resultados}

Os resultados do ensaio MTT nas diferentes concentrações utilizadas estão representados na figura 1. Em uma diluição 1:1 não houve diferença estatística entre os cimentos testados $(P>0,05)$. Na diluição 1:2, o AH Plus apresentou menor toxicidade quando comparado aos demais cimentos testados $(P<0,05)$. Nas diluições 1:4 e 1:8 o MTA Fillapex apresentou maior citotoxicidade quando comparado ao AH Plus e ao EndoSeal $(P<0,05)$ e não foram observadas diferenças estatísticamente significantes entre o AH Plus e o EndoSeal $(P>0,05)$.

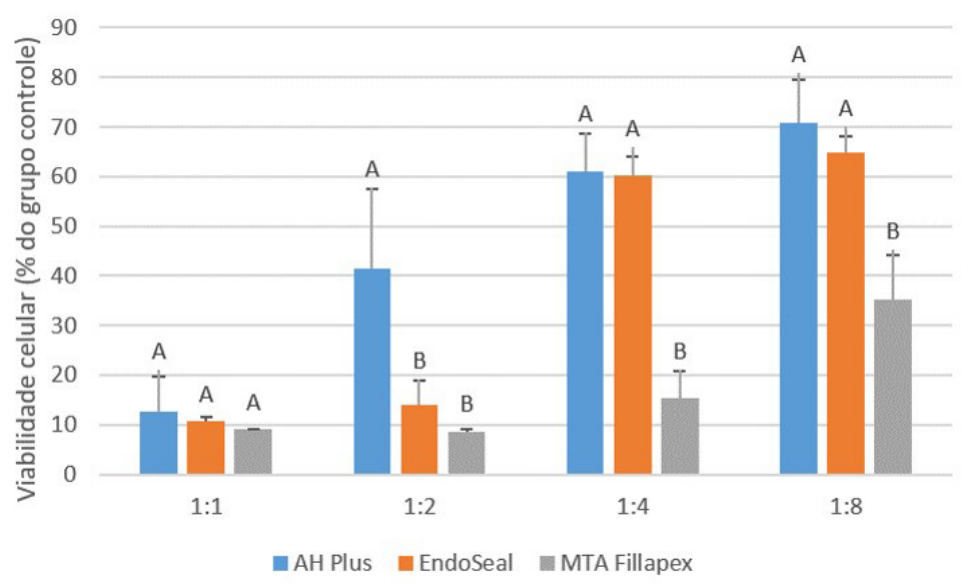

Figura 1. Os efeitos citotóxicos após exposição das diluições dos cimentos endodônticos aos fibroblastos humanos imortalizados da linhagem MRC-5. Os resultados são expressos como média e desvio padrão em diferentes diluições. Letras diferentes indicam diferenças estatisticamente significativas $(P<0,05)$ na mesma diluição 


\section{Discussão}

Os resultados mostraram que a citotoxicidade de todos os cimentos endodônticos testados foi dose dependente, uma vez que a porcentagem de células viáveis aumentou quanto mais foi diluído o meio. Contudo em nenhuma das concentrações testadas as amostras foram estatisticamente iguais ao grupo controle negativo. Devido às excelentes propriedades físicoquímicas e biológicas do MTA, novos materiais compostos pelo agregado trióxido mineral surgiram recentemente. ${ }^{13-16}$ Contudo as diversas composições diferentes e as proporções distintas de MTA nas formulações promovem resultados de citotoxicidade variados a estes cimentos com o mesmo componente base..$^{14,17}$

O MTA Fillapex foi o material que apresentou a maior citotoxicidade em valores absolutos em todas as diluições e entre todos os cimentos endodônticos testados. O MTA Fillapex apresentou toxicidade estatisticamente superior a $\mathrm{AH}$ Plus e oa Endoseal nas concentrações de 1:4 e 1:8; dessa forma, a hipótese nula foi rejeitada. A baixa biocompatibilidade deste material já foi previamente relatada na literatura. ${ }^{5,9-13} \mathrm{Os}$ componentes presentes na formulação MTA Fillapex, tais como resina de salicilato, resina de diluição e a sílica, podem estar relacionados com tais resultados que constatam a baixa tolerância deste material na cultura de células de fibroblastos. Além disso, o MTA Fillapex provavelmente tem uma proporção desequilibrada entre resinas e MTA, com valores menores de MTA em sua composição, exibindo então, em menor quantidade, as boas propriedades biológicas reconhecidas deste material. Este cimento endodôntico também possui um tempo de presa prolongado e, por isso, pode se solubilizar no meio, possivelmente liberando estes componentes citotóxicos já citados, como as resinas de sua composição, mecanismo que também pode contribuir para as baixas taxas de viabilidade celular constatadas neste experimento. ${ }^{9,18-20}$

O Endoseal é um material obturador ainda pouco estudado na Endodontia. ${ }^{14,16,17}$ Ele também possui MTA em sua composição, assim como o MTA Fillapex. No entanto, este cimento não possui nenhum componente conhecidamente citotóxico em sua formulação, o que pode contribuir os melhores resultados deste material quando comparado ao MTA Fillapex em 2 das 4 diluições testadas. Assim como no estudo de Collado-González et al. ${ }^{14}$ o Endoseal apresentou baixos níveis de viabilidade celular nas concentrações 1:1 e 1:2, contudo estes níveis melhoraram consideravelmente nas concentrações 1:4 e 1:8. Este cimento e o AH Plus foram os materiais que apresentaram os melhores resultados estatisticamente em três das quatro diluições testadas. Contudo, no estudo de Kim e Shin, ${ }^{16}$ o Endoseal apresentou resultados superiores aos do AH Plus, o que difere dos resultados encontrados no presente estudo, onde estatisticamente não houve diferença entre estes materiais. O Endoseal dispensa manipulação, pois se apresenta comercialmente em uma seringa, pronto para uso. Este fato evita erro de dosagem do material, que poderia gerar um produto final com uma composição desproporcional, e assim influenciar as propriedades biológicas, físicas e químicas do cimento endodôntico.

Como os cimentos endodônticos são compostos de uma mistura que endurece através de uma reação química, a liberação de componentes tóxicos durante esta reação de presa química torna o material menos tolerado pelos tecidos periapicais. ${ }^{21}$

Diversos métodos vêm sendo utilizados a fim de avaliar os efeitos citotóxicos dos cimentos endodônticos. ${ }^{5,9,11-17}$ No presente estudo, a viabilidade celular foi determinada através do ensaio de MTT, que é baseado na habilidade das enzimas desidrogenases mitocondriais, presentes nas células vivas, em converter o sal amarelo tetrazólio para cristais de formazan lilás. As vantagens deste método são sua simplicidade, velocidade, precisão e elevada reprodutibilidade. ${ }^{22,23}$ Apesar de não existir sempre uma correlação positiva entre o número de células viáveis e a redução do sal do MTT, o que é considerado uma das limitações de se utilizar apenas um parâmetro para medir a toxicidade de um biomaterial, este teste é amplamente aceito e utilizado em trabalhos com este objetivo na Endodontia..$^{5,11-13,24-26}$ Alguns autores sugerem a realização de ensaios multiparamétricos, com diferentes testes de viabilidade celular. ${ }^{27,28}$ Esse método pode aumentar a chance de detecção dos efeitos citotóxicos, permitindo a correlação de diferentes parâmetros, o que pode fornecer pistas sobre os mecanismos de toxicidade. ${ }^{27}$

Neste estudo, a citotoxicidade dos cimentos endodônticos foi verificada em fibroblastos MRC-5 humanos. Os fibroblastos são os principais constituintes do tecido conjuntivo, sendo o ligamento periodontal diretamente envolvido, também no selamento biológico apical. ${ }^{29}$

No presente estudo, todos os cimentos endodônticos apresentaram potencial citotóxico em cultura de fibroblastos. Este estudo apresenta as limitações decorrentes de um estudo in vitro, sendo necessária a realização de estudos futuros avaliando a biocompatibilidade in vivo e outras propriedades físico-químicas e biológicas dos materiais avaliados.

\section{Conclusão}

A citotoxicidade dos cimentos endodônticos avaliados foi dose dependente. O Endoseal apresentou resultados estatisticamente superiores aos do MTA Fillapex em duas das quatro diluições testadas, apesar destes cimentos possuírem o mesmo componente base. Além disso, o AH Plus apresentou citotoxicidade estatisticamente inferior aos dois cimentos à base de MTA em uma das quatro diluições avaliadas.

Rev. Bras. Odontol., Rio de Janeiro, v. 74, n. 1, p. 27-30, jan./mar. 2017 


\section{Referências}

1. Barthel CR, Zimmer S, Wussogk R, Roulet JF. Long-Term bacterial leakage along obturated roots restored with temporary and adhesive fillings. J Endod. 2001;27(9):559-62.

2. Lopes HP, Siqueira Jr JF. Endodontia - Biologia e Técnica. $4^{\text {a }}$ ed. Rio de Janeiro (RJ): Guanabara Koogan, 2015.

3. Ricucci D. Apical limit of root canal instrumentation and obturation, part 1. Literature review. Int Endod J. 1998;31(6):384-93.

4. Ricucci D, Rôças IN, Alves FR, Loghin S, Siqueira JF Jr. Apically extruded sealers: fate and influence on treatment outcome. J Endod. 2016;42(2):243-9.

5. Silva EJ, Zaia AA, Peters OA. Cytocompatibility of calcium silicate-based sealers in a three-dimensional cell culture model. Clin Oral Investig. In press 2016. 6. Parirokh M, Torabinejad M. Mineral trioxide aggregate: a comprehensive literature review-part I: chemical, physical and antibacterial properties. J Endod. 2010a;36(1):16-27.

7. Torabinejad M, Parirokh M. Mineral trioxide aggregate: a comprehensive literature review-part II: leakage and biocompatibility investigations. J Endod. 2010;36(2):190-202.

8. Parirokh M, Torabinejad M. Mineral trioxide aggregate: a comprehensive literature review-Part III: Clinical applications, drawbacks, and mechanism of action. J Endod. 2010;36(3):400-13.

9. Silva EJ, Santos CC, Zaia AA. Long-term cytotoxic effects of contemporary root canal sealers. J Appl Oral Sci. 2013;21(1):43-7.

10. Baraba A, Pezelj-Ribaric S, Roguljić M, Miletic I. Cytotoxicity of Two Bioactive Root Canal Sealers. Acta Stomatol Croat. 2016;50(1):8-13.

11. Zhou HM, TF D, Shen Y, Wang ZJ, Zheng YF, Haapasalo M. In vitro cytotoxicity of calcium silicate-containing endodontic sealers. J Endod. 2015;41(1):56-61. 12. Rodríguez-Lozano FJ, García-Bernal D, Oñate-Sánchez RE, Ortolani-Seltenerich PS, Forner L, Moraleda JM. Evaluation of cytocompatibility of calcium silicate-based endodontic sealers and their effects on the biological responses of mesenchymaldental stem cells. Int Endod J. 2017;50(1):67-76.

13. Bin CV, Valera MC, Camargo SE, Rabelo SB, Silva GO, Balducci I, et al. Cytotoxicity and genotoxicity of root canal sealers based on mineral trioxide aggregate. J Endod. 2012;38(4):495-500.

14. Collado-González M, García-Bernal D, Oñate-Sánchez RE, Ortolani-Seltenerich PS, Lozano A, Forner L, et al. Biocompatibility of three new calcium silicate -based endodontic sealers on human periodontal ligament stem cells. Int Endod J. In press 2016.

15. Lim ES, Park YB, Kwon YS, Shon WJ, Lee KW, Min KS. Physical properties and biocompatibility of an injectable calcium-silicate-based root canal sealer: in vitro and in vivo study. BMC Oral Health. 2015;15(1):129.
16. Kim RJ, Shin JH. Cytotoxicity of a novel mineral trioxide aggregate-based root canal sealer [corrected]. Dent Mater J. 2014;33(3):313-8. Erratum in: Dent Mater J. 2014; 33(4):576.

17. Güven EP, Yalvaç ME, Kayahan MB, Sunay H, Şahın F, Bayirli G. Human tooth germ stem cell response to calcium-silicate based endodontic cements. J Appl Oral Sci. 2013;21(4):351-7.

18. Vitti RP, Prati C, Sinhoreti MA, Zanchi CH, Souza E Silva MG, Ogliari FA, et al. Chemical-physical properties of experimental root canal sealers based on butyl ethylene glycol disalicylate and MTA. Dent Mater. 2013;29(12):1287-94.

19. Amoroso-Silva PA, Guimarães BM, Marciano MA, Duarte MA, Cavenago $\mathrm{BC}$, Ordinola-Zapata R, et al. Microscopic analysis of the quality of obturation and physical properties of MTA Fillapex. Microsc Res Tech. 2014;77(12):1031-6. 20. Silva EJ, Perez R, Valentim RM, Belladonna FG, De-Deus GA, Lima IC, et al. Dissolution, dislocation and dimensional changes of endodontic sealers after a solubility challenge: A micro-CT approach. Int Endod J. In Press 2016.

21. Hargreaves KM, Cohen S. Pathways of the pulp. 10th ed. St. Louis (MO): Mosby Elsevier; 2006. p. 263.

22. Sepet E, Pinar A, Ilhan B, Ulukapi I, Bilir A, Tuna S. Cytotoxic effects of calcium hydroxide and mineral trioxide aggregate on $3 \mathrm{~T} 3$ fibroblast cell line in vitro. Quintessence Int. 2009;40(8):e55-61.

23. Malkoc S, Corekci B, Ulker HE, Yalçin M, Sengün A. Cytotoxic effects of orthodontic composites. Angle Orthod. 2010;80(4):571-6.

24. Silva EJ, Accorsi-Mendonça T, Almeida JF, Ferraz CC, Gomes BP, Zaia AA. Evaluation of cytotoxicity and up-regulation of gelatinases in human fibroblast cells by four root canal sealers. Int Endod J. 2012;45(1):49-56.

25. Candeiro GT, Moura-Netto C, D’Almeida-Couto RS, Azambuja-Júnior N, Marques MM, Cai S, et al. Cytotoxicity, genotoxicity and antibacterial effectiveness of a bioceramic endodontic sealer. Int Endod J. In press 2015.

26. Silva EJ, Neves AA, De-Deus G, Accorsi-Mendonça T, Moraes AP, Valentim RM, et al. Cytotoxicity and gelatinolytic activity of a new silicon-based endodontic sealer. J Appl Biomater Funct Mater. 2015;13(4):e376-80.

27. De-Deus G, Canabarro A, Alves G, Linhares A, Senne MI, Granjeiro JM. Optimal cytocompatibility of a bioceramic nanoparticulate cement in primary human mesenchymal cells. J Endod. 2009;35(10):1387-90.

28. Scelza MZ, Linhares AB, da Silva LE, Granjeiro JM, Alves GG. A multiparametric assay to compare the cytotoxicity of endodontic sealers with primary human osteoblasts. Int Endod J. 2012;45(1):12-8.

29. Silva LA, Barnett F, Pumarola-Suñe J, Cañadas PS, Nelson Filho P, Silva RA. Sealapex Xpress and RealSeal XT feature tissue compatibility in vivo. J Endod. 2014;40(9):1424-8.

\section{Mini Currículo e Contribuição dos Autores}

1. Fernanda Cunha Marins - estudante de Odontologia. Contribuição: aquisição dos dados, interpretação dos dados, procedimentos técnicos.

2. Carina Taboada Ronconi - estudante de Odontologia. Contribuição: aquisição dos dados, interpretação dos dados, procedimentos técnicos.

3. Flávia Medeiros Saavedra - CD e MSc. Contribuição: aquisição dos dados, interpretação dos dados, procedimentos técnicos, redação do manuscrito.

4. Ana Beatriz Machado Lima - MSc. Contribuição: procedimentos técnicos; redação do manuscrito.

5. Alexandre Augusto Zaia - CD e PhD. Contribuição: participação científica e intelectual efetiva para o estudo; concepção e delineamento; revisão crítica.

6. Edson Jorge Lima Moreira - CD e PhD. Contribuição: participação científica e intelectual efetiva para o estudo; concepção e delineamento; revisão crítica

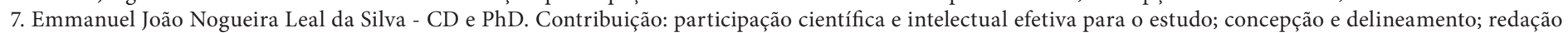
do manuscrito; revisão crítica; aprovação final.

Recebido em: 16/12/2016 / Aprovado em: 15/02/2017

Autor Correspondente

Emmanuel João Nogueira Leal da Silva

E-mail: nogueiraemmanuel@hotmail.com 